\title{
Intraoperative image guidance for the surgical treatment of adult spinal deformity
}

\author{
Venkat Boddapati ${ }^{1}$, Joseph M. Lombardi ${ }^{1}$, Hikari Urakawa ${ }^{2}$, Ronald A. Lehman ${ }^{1}$ \\ ${ }^{1}$ The Spine Hospital, New York-Presbyterian/Columbia University Irving Medical Center, New York, NY, USA; ${ }^{2}$ Hospital for Special Surgery, New \\ York, NY, USA \\ Contributions: (I) Conception and design: V Boddapati, JM Lombardi, R Lehman; (II) Administrative support: None; (III) Provision of study materials \\ or patients: None; (IV) Collection and assembly of data: V Boddapati; (V) Data analysis and interpretation: V Boddapati, JM Lombardi, RA Lehman; \\ (VI) Manuscript writing: All authors; (VII) Final approval of manuscript: All authors. \\ Correspondence to: Venkat Boddapati, MD. The Spine Hospital, New York-Presbyterian, 5141 Broadway Avenue, New York, NY 10034, USA. \\ Email:vb2471@cumc.columbia.edu.
}

\begin{abstract}
Operative management of adult spinal deformity (ASD) has been increasing in recent years secondary to an aging society. The advance of intraoperative image guidance, such as the development of navigation and robotics systems has contributed to the growth and safety of ASD surgery. Currently, intraoperative image guidance is mainly used for pedicle screw placement and the evaluation of alignment correction in ASD surgery. Though it is expected that the use of navigation and robotics would result in increasing pedicle screw accuracy as reported in other spine surgeries, there are no well-powered studies specifically focusing on ASD surgery. Currently, deformity correction relies heavily on preoperative planning, however, a few studies have shown the possibility that intraoperative image modalities may accurately predict postoperative spinopelvic parameters. Future developments of intraoperative image guidance are needed to overcome the remaining challenges in ASD surgery such as radiation exposure to patient and surgeon. More novel imaging modalities may result in evolution in ASD surgery. Overall there is a paucity of literature focusing on intraoperative image guidance in ASD surgery, therefore, further studies are warranted to assess the efficacy of intraoperative image guidance in ASD surgery. This narrative review sought to provide the current role and future perspectives of intraoperative image guidance focusing on ASD surgery.
\end{abstract}

Keywords: Adult spinal deformity (ASD); image guidance; navigation; robotics

Submitted Mar 23, 2020. Accepted for publication Jun 11, 2020.

doi: $10.21037 / \mathrm{atm}-20-2765$

View this article at: http://dx.doi.org/10.21037/atm-20-2765

\section{Introduction}

Adult spinal deformity (ASD) is a degenerative disease with three-dimensional deformity in the alignment of the spinal column throughout the aging process $(1,2)$. Clinical presentation of ASD varies greatly depending on the type and severity from minimal or no symptoms to severe back and leg pain, with malalignment resulting in a disability of standing, walking, eating, sleeping (3). It can have a debilitating impact on overall health often exceeding the disability of more recognized chronic diseases $(4,5)$. The prevalence of spinal deformity is high, with reports of an incidence of $65 \%$ in those older than 60 years (6). Along with an aging society, the demand for the treatment of ASD has been increasing.

The history of deformity surgery began in the early 20th century and the challenge to correct deformity began in the late 20th century with Harrington rods and hooks used to distract and compress across deformity $(7,8)$. However, inherently, surgical treatment was not popular in ASD because it was associated with a relatively high morbidity rate resulting in a large amount of blood loss, long operative 

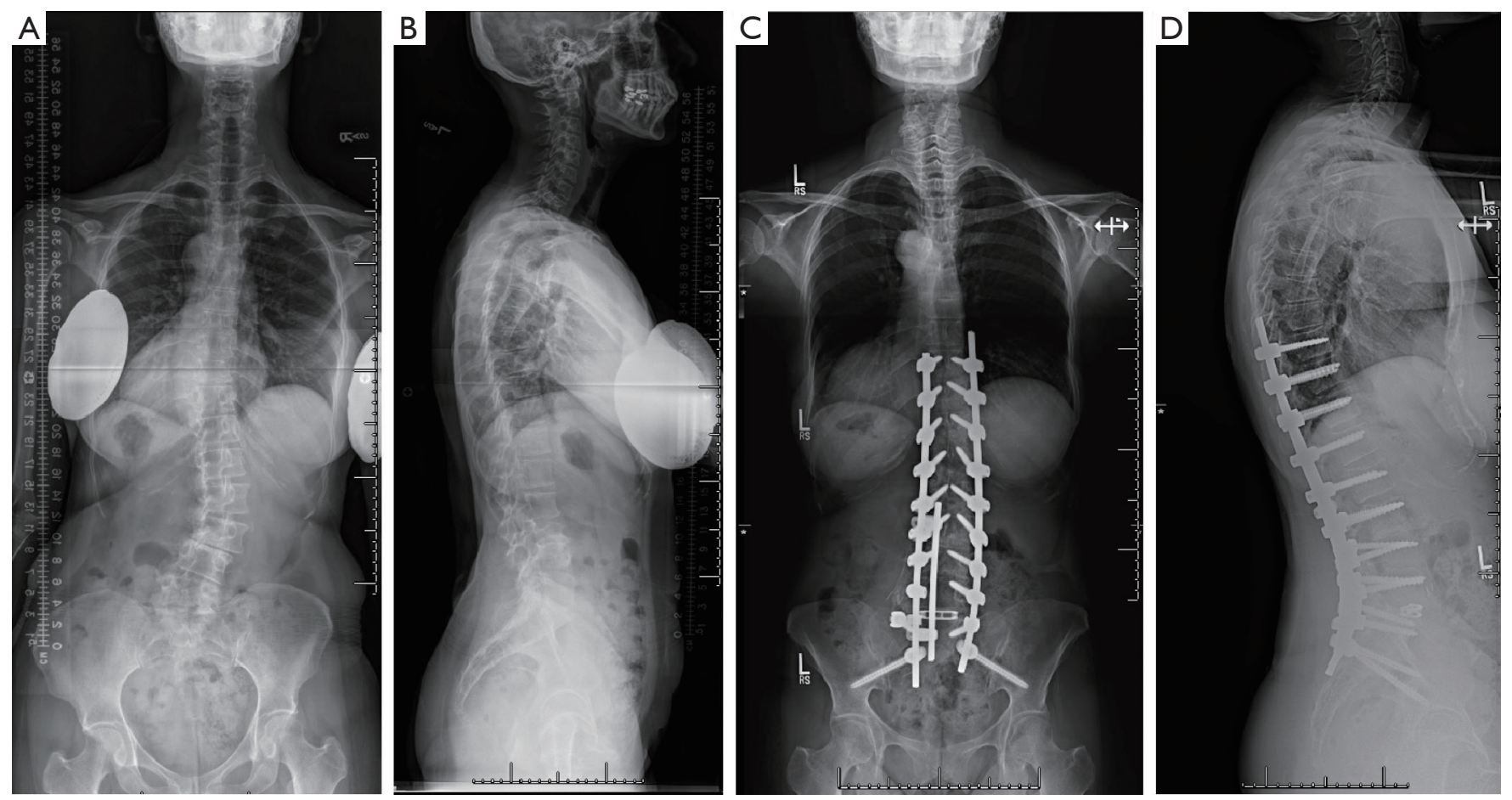

Figure 1 Representative images of adult spinal deformity in a 56-year-old female presenting with back pain and neurogenic claudication and posteroanterior and lateral radiographs $(\mathrm{A}, \mathrm{B})$ with thoracolumbar degenerative scoliosis in the setting of diffuse spondylosis. Postoperative posteroanterior and lateral radiographs (C,D) show T10-Ilium fusion with two-level TLIF (L3-4, L4-5).

duration, and complications. However, improvements in anesthesia and critical care, surgical techniques, and instrumentation has led to remarkable advances in ASD surgery with patients able to undergo safer, faster, and more reproducible surgery (9). Around the same time, using radiographic parameters, the Scoliosis Research Society (SRS)-Schwab classification established a framework for characterizing spinopelvic malalignment and providing realignment targets for surgeons, which has led to an explosion in ASD volume (10).

The goal of ASD surgery is to correct the deformity based on appropriate spinopelvic parameters as these parameters have been found to correlate with patientreported outcomes $(11,12)$. Current surgical techniques for ASD are based on posterior fusion with pedicle screws and rods, if necessary, in conjunction with lateral and anterior fusion or osteotomy (9) (Figure 1). Intraoperative image guidance is essential in those procedures. Newer image modalities such as navigation or robotics are gaining traction in ASD surgery as well as other spine surgeries.

The aim of the present narrative review is to assess the current role and future perspectives of intraoperative image guidance focusing on ASD surgery.

\section{Current role of intraoperative image guidance in ASD surgery}

\section{Pedicle screw placement}

Segmental pedicle screw fixation is the anchor to correct deformity in ASD surgery. It enables deformity correction in multiple planes with rigid fixation (13). Intraoperative image guidance is particularly useful in ASD surgery where there is a three-dimensional deformity with dysmorphic pedicles that makes visualizing normal anatomical landmarks for pedicle screw insertion difficult.

Pedicle screws are traditionally placed using a freehand technique, mostly with fluoroscopic guidance $(14,15)$. Currently, navigation technology has been widely used in various spine surgeries and most studies reported to increase the accuracy of pedicle screw placement (Table 1). Several studies have suggested that the utilization of navigation resulted in improved accuracy of pedicle 


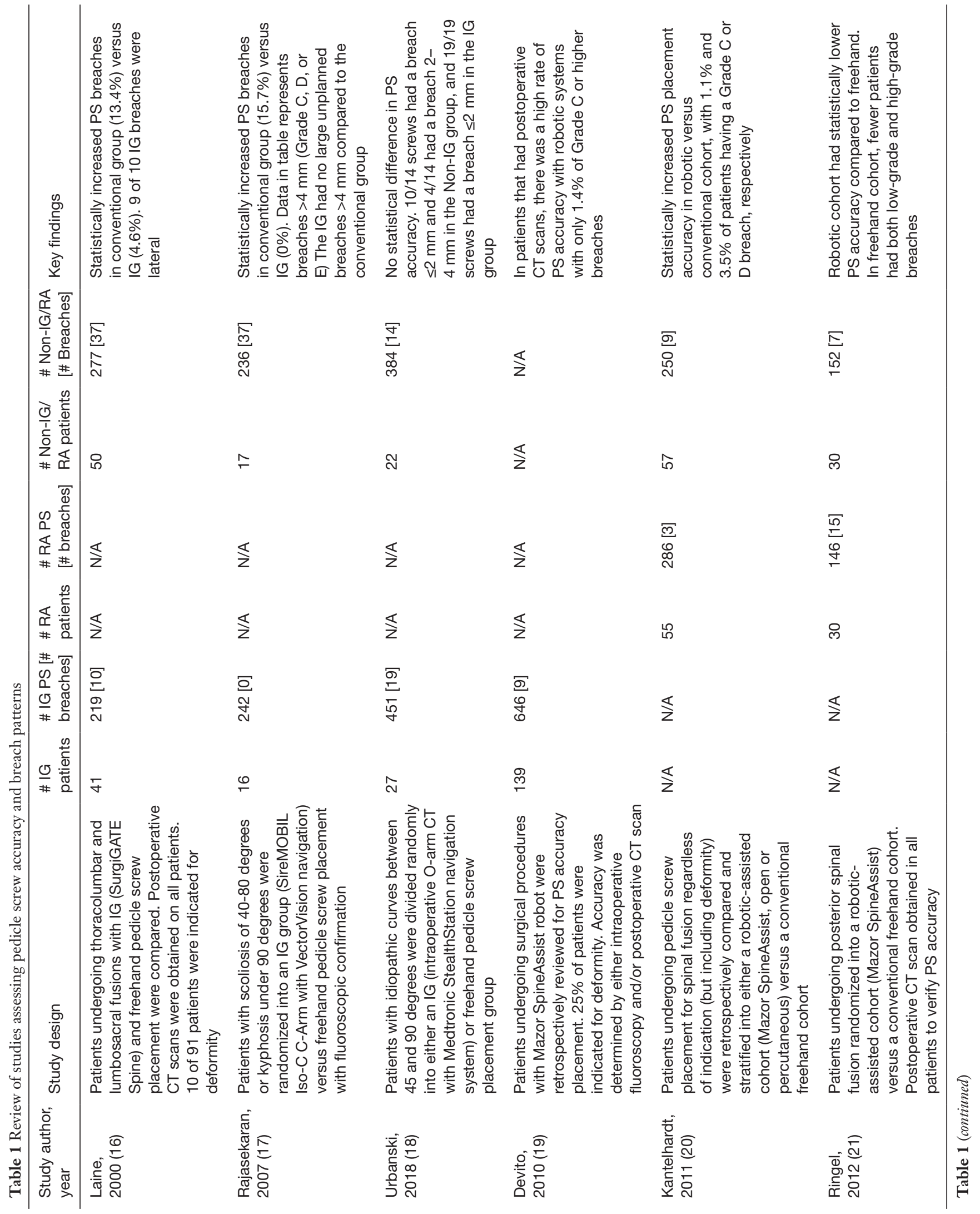




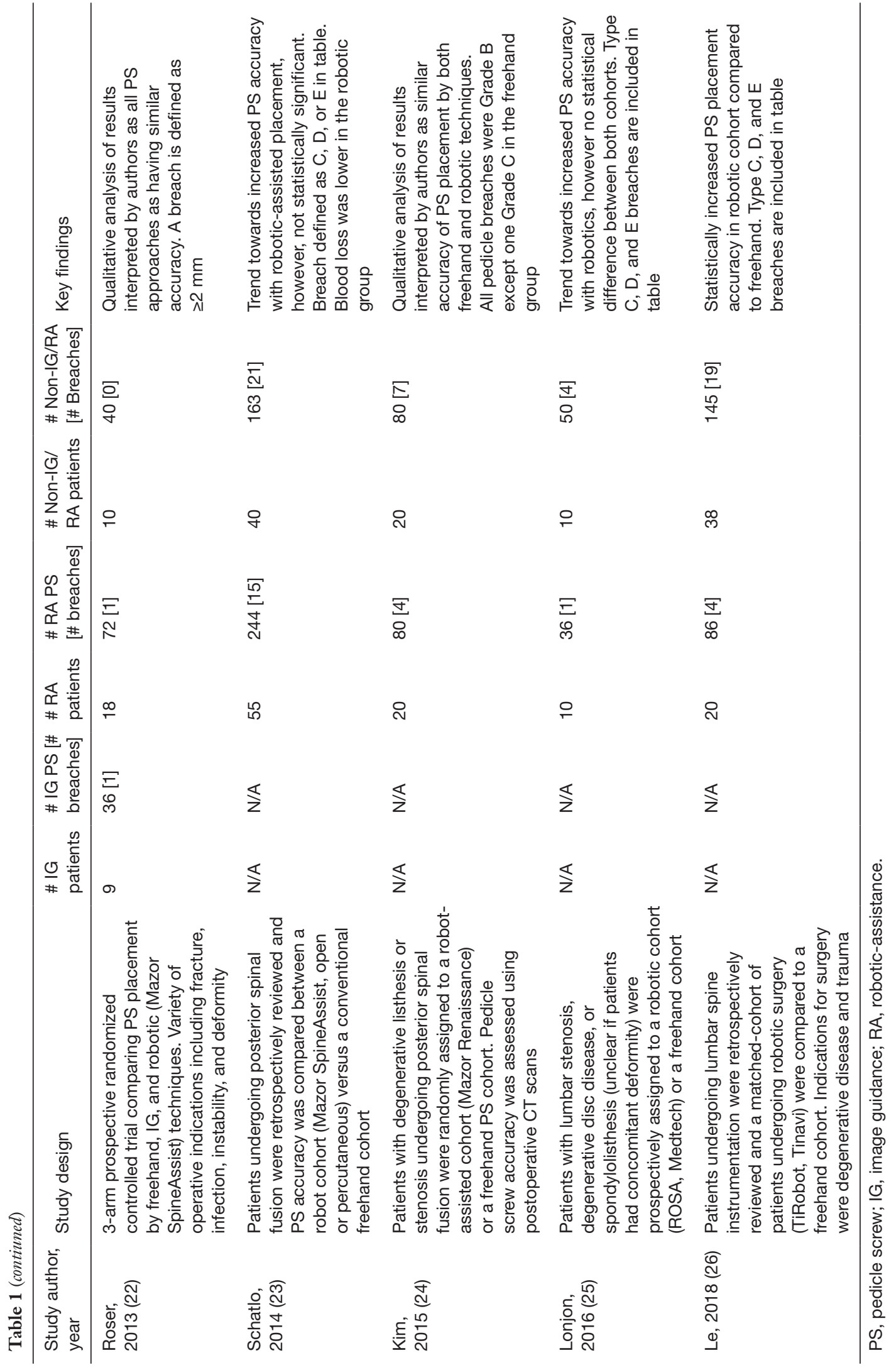



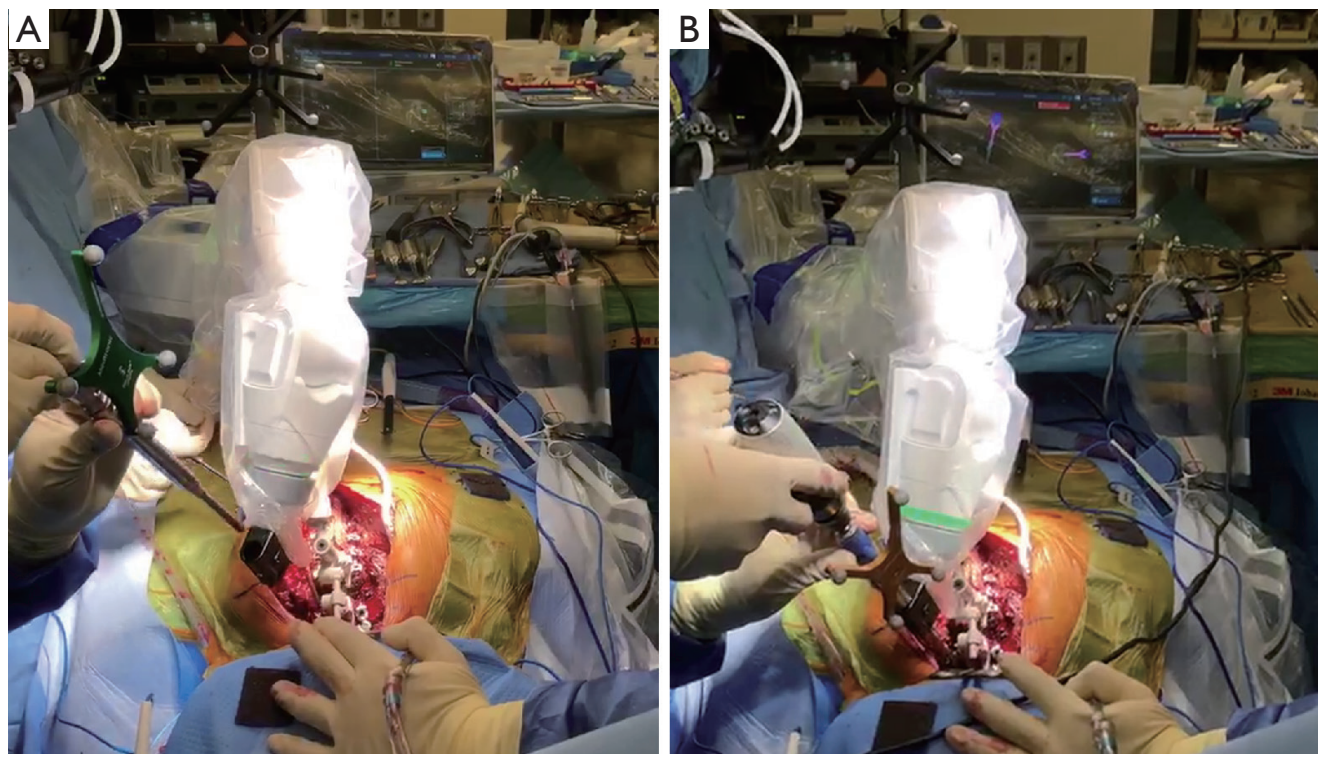

Figure 2 Intraoperative utilization of robotics. (A) Localization of robotic arm to trajectory for planned instrumented pedicle, (B) pedicle screw placement through navigated robotic arm.

screw placement in deformity surgery, compared to the conventional fluoroscopy. Rajasekaran et al. performed a randomized clinical trial in 33 patients (27 with scoliosis and 6 with kyphosis due to tuberculosis or Scheuermann's disease) and showed pedicle breaches were significantly fewer in patients using navigation group (2\%) compared to those in fluoroscopy group (23\%) (17). While the navigated cohort in this study did include adult patients up to 52 years old, the average of this cohort was 19.6 years, and the data was not granular enough to perform analysis on the ASD cohort in isolate. Jin et al. reported the accuracy rate of pedicle screw placement was significantly higher in patients using navigation (79\% with breach less than $2 \mathrm{~mm}$ ) compared to that in patients using fluoroscopy $(67 \%$ with breach less than $2 \mathrm{~mm}$ ) for 32 patients with dystrophic neurofibromatosis type 1-associated scoliosis (27). However, these are studies focusing on primarily pediatric deformity surgery, and not specifically ASD surgery. This patient population is similar to that of an ASD cohort in terms of three-dimensional deformity and dysmorphic pedicles with tilt and rotation, however, there are differences in the diameter or yielding of the pedicle and the presence of osteopenia/osteoporosis. To our knowledge, there is currently a lack of literature focusing specifically on isolated ASD surgery, though there are a couple of studies including ASD patients as a small portion of their subjects. Further investigations focusing on ASD surgery are warranted to clarify the benefits of navigation for the accuracy of pedicle screw placement in ASD surgery.

In addition to image guidance, robotic technology is also rapidly gaining traction (Figure 2). Some studies reported the utility of robotics statistically increased pedicle screw accuracy in spine surgery, though the overall findings are still controversial (Table 1). Little literature has investigated the pedicle screw accuracy focusing on deformity surgery using robotics. Macke et al. retrospectively examined robotic-assisted pedicle screw placement in 50 patients with adolescent idiopathic scoliosis and reported that the proper use of image-guided robot-assisted surgery can improve the accuracy and safety of thoracic pedicle screw placement, resulting in pedicle screws with a breach of greater than $2 \mathrm{~mm}$ were $7.2 \%$ (28). Further studies are needed to assess the advantages of robotics in ASD surgery, specifically related to pedicle screw placement accuracy.

\section{Alignment correction}

Alignment correction is the nucleus of ASD surgery. With pedicle screws connected to dual rods, the deformity is corrected using various techniques including translation, distraction-compression, rod de-rotation, direct vertebral de-rotation, cantilever, in situ bending, or vertebral coplanar 
alignment (29). This procedure does not heavily depend on intraoperative image, as the majority of work is dependent on the surgeon's execution of the preoperative realignment plan based on preoperative imaging. Intraoperative imaging provides some indication as to the degree of correction. However, standard fluoroscopy does not show whether the intraoperative correction exactly matches the preoperative plan due to the patient's position and imaging range during surgery. Few studies have investigated the utility of intraoperative imaging to assess postoperative alignment in deformity surgery.

Lehman et al. demonstrated that all curve correction and balance parameters measured on intraoperative long-cassette scoliosis films correlated with those measured on immediate postoperative standing film in 44 patients with adolescent idiopathic scoliosis (30). Oren et al. first evaluated the correlation between intraoperative spinopelvic parameters measured on intraoperative films and postoperative global alignment in ASD patients (31). The intraoperative film was calibrated by the validated way using pelvic incidence and sacral to bicoxofemoral axis distance (32). They showed intraoperative measurements of TPA, T4PA, and T9PA strongly correlated with postoperative global alignment. However, this process remains cumbersome, can take several minutes, and increases the risk of contamination of the sterile field with the introduction of numerous, nonsterile moving parts. There is still a paucity of literature on this topic, therefore, further studies are needed to predict postoperative alignment exactly by intraoperative image guidance. The advancement of intraoperative image guidance may enable more precise and efficient assessment of it.

\section{Future perspectives of intraoperative image guidance in ASD surgery}

In the past two decades, ASD surgery has made rapid progress in parallel with the advancement of intraoperative imaging, image guidance, and robotics. Surgical treatment had limited applicability to ASD patients before, however, recently ASD patients may now benefit from less invasive treatments with outcomes that demonstrate an improved the quality of life (33). Nevertheless, there are some challenging problems remaining, notably that approximately $70 \%$ of patients experienced at least one complication postoperatively, and approximately $30 \%$ required at least one revision procedure (34).
In terms of intraoperative image guidance, decreasing radiation exposure is of great importance for both patients, surgeons, and operating room staff (35). In addition to radiation during surgery, ASD patients are often exposed to radiation in the form of pre- and post-operative full-length standing radiographs, and CT scans to monitor alignment over time. On the other hand, orthopedic surgeons, and in particular spine surgeons, are routinely exposed to intraoperative radiation resulting in higher cancer risk compared to surgeons in other fields (36). Several studies demonstrated the use of navigation significantly, which decreased radiation exposure compared to the use of conventional fluoroscopy use in spine surgery (Table 2). Usually, many more pedicle screws are inserted in ASD surgery compared to other spine surgeries. Therefore, the decrease in radiation exposure due to navigation use may be particularly advantageous in ASD surgery, though there is a paucity of literature focusing specifically on this subset of patients.

Although the development in intraoperative image guidance is rapidly progressing in recent years, future advancements are anticipated. Currently, there is little compatibility amongst navigated tools across companies. Additionally, adoption of image guided and navigated operating room setups may be hindered by the initial cost and maintenance of purchasing of the system (43). If these issues are solved, these newer modalities will expand over even more. Moreover, novel intraoperative image guidance, such as augmented reality (AR), are in development and may work in conjunction with future robotics technology. This may enable surgeons to obtain the information of real-time navigation without having to look away from the patient.

\section{Conclusions}

The advance of intraoperative image guidance and robotics, along with all advances associated with surgical treatment, has led to the improved safety and effectiveness of ASD surgery in recent years. Navigation and robotic system are expected to improve outcomes in ASD surgery as reported in other spine surgeries, however, there is currently a paucity of literature focusing on intraoperative image guidance in this patient population. Further studies with a specific focus on ASD surgery are warranted to assess the efficacy of intraoperative image guidance in ASD surgery. 


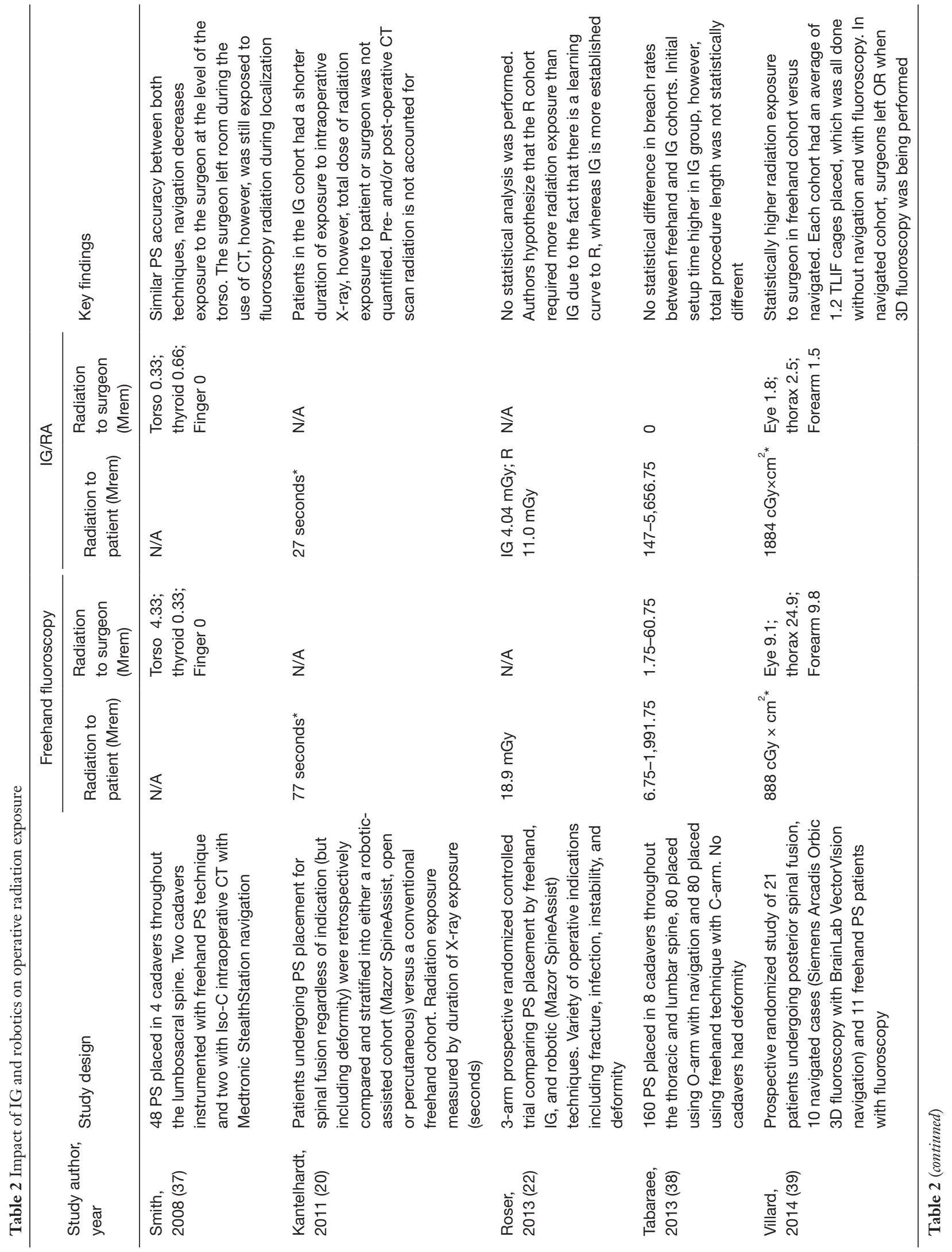









\section{Acknowledgments}

Funding: None.

\section{Footnote}

Provenance and Peer Review: This article was commissioned by the Guest Editor (Dr. Sheeraz Qureshi) for the series "Current State of Intraoperative Imaging" published in Annals of Translational Medicine. The article was sent for external peer review organized by the Guest Editor and the editorial office.

Conflicts of Interest: All authors have completed the ICMJE uniform disclosure form (available at http://dx.doi. org/10.21037/atm-20-2765). The series "Current State of Intraoperative Imaging” was commissioned by the editorial office without any funding or sponsorship. RAL reports personal fees and other from Medtronic, personal fees and other from Stryker, outside the submitted work. The authors have no other conflicts of interest to declare.

Ethical Statement: The authors are accountable for all aspects of the work in ensuring that questions related to the accuracy or integrity of any part of the work are appropriately investigated and resolved.

Open Access Statement: This is an Open Access article distributed in accordance with the Creative Commons Attribution-NonCommercial-NoDerivs 4.0 International License (CC BY-NC-ND 4.0), which permits the noncommercial replication and distribution of the article with the strict proviso that no changes or edits are made and the original work is properly cited (including links to both the formal publication through the relevant DOI and the license). See: https://creativecommons.org/licenses/by-nc-nd/4.0/.

\section{References}

1. Youssef JA, Orndorff DO, Patty CA, et al. Current status of adult spinal deformity. Global Spine J 2013;3:51-62.

2. Good CR, Auerbach JD, O'Leary PT, et al. Adult spine deformity. Curr Rev Musculoskelet Med 2011;4:159-67.

3. Schwab F, Lafage V, Farcy JP, et al. Surgical rates and operative outcome analysis in thora-columbar and lumbar major adult scoliosis: application of the new adult deformity clas-sification. Spine (Phila $\mathrm{Pa} 1976$ ) 2007;32:2723-30.
4. Bess S, Line B, Fu KM, et al. The health impact of symptomatic adult spinal deformity: com-parison of deformity types to United States population norms and chronic diseases. Spine (Phila Pa 1976) 2016;41:224-33.

5. Pellisé F, Vila-Casademunt A, Ferrer $M$, et al. Impact on health related quality of life of adult spinal deformity (ASD) compared with other chronic conditions. Eur Spine J 2015;24:3-11.

6. Schwab F, Dubey A, Gamez L, et al. Adult scoliosis: prevalence, SF-36, and nutritional pa-rameters in an elderly volunteer population. Spine (Phila Pa 1976) 2005;30:1082-5.

7. Hibbs RA. A report of fifty-nine cases of scoliosis treated by the fusion operation. J Bone Joint Surg Am 1924;6:3-37.

8. Harrington PR. Treatment of scoliosis. Correction and internal fixation by spine instrumenta-tion. J Bone Joint Surg Am 1962;44-A:591-610.

9. Smith JS, Shaffrey CI, Ames CP, et al. Treatment of adult thoracolumbar spinal deformity: past, present, and future. J Neurosurg Spine 2019;30:551-67.

10. Schwab F, Ungar B, Blondel B, et al. Scoliosis Research Society-Schwab adult spinal deformity classification: a validation study. Spine (Phila Pa 1976) 2012;37:1077-82.

11. Schwab FJ, Blondel B, Bess S, et al. Radiographical spinopelvic parameters and disability in the setting of adult spinal deformity: a prospective multicenter analysis. Spine (Phila Pa 1976) 2013;38:E803-12.

12. Smith JS, Klineberg E, Schwab F, et al. Change in classification grade by the SRS-Schwab adult spinal deformity classification predicts impact on healthrelated quality of life measures. Spine (Phila Pa 1976) 2013;38:1663-71.

13. Steinmetz MP, Rajpal S, Trost G. Segmental spinal instrumentation in the management of scoliosis. Neurosurgery 2008;63:131-8.

14. Suk SI, Kim WJ, Lee SM, et al. Thoracic pedicle screw fixation in spinal deformities: are they really safe? Spine (Phila Pa 1976) 2001;26:2049-57.

15. Kim YJ, Lenke LG, Bridwell KH, et al. Free hand pedicle screw placement in the thoracic spine: is it safe? Spine (Phila Pa 1976) 2004;29:333-42.

16. Laine T, Lund T, Ylikoski M, et al. Accuracy of pedicle screw insertion with and without computer assistance: a randomised controlled clinical study in 100 consecutive patients. Eur Spine J 2000;9:235-40.

17. Rajasekaran S, Vidyadhara S, Ramesh P, et al. Randomized clinical study to compare the accuracy of navigated and 
non-navigated thoracic pedicle screws in deformity correction surgeries. Spine (Phila Pa 1976) 2007;32:E56-64.

18. Urbanski $W$, Jurasz $W$, Wolanczyk $M$, et al. Increased Radiation but No Benefits in Pedicle Screw Accuracy With Navigation versus a Freehand Technique in Scoliosis Surgery. Clin Orthop Relat Res 2018;476:1020-7.

19. Devito DP, Kaplan L, Dietl R, et al. Clinical acceptance and accuracy assessment of spinal implants guided with SpineAssist surgical robot: retrospective study. Spine 2010;35:2109-15.

20. Kantelhardt SR, Martinez R, Baerwinkel S, et al. Perioperative course and accuracy of screw positioning in conventional, open robotic-guided and percutaneous robotic-guided, pedicle screw placement. Eur Spine J 2011;20:860-8.

21. Ringel F, Stüer C, Reinke A, et al. Accuracy of robotassisted placement of lumbar and sacral pedicle screws: a prospective randomized comparison to conventional freehand screw implantation. Spine (Phila Pa 1976) 2012;37:E496-501.

22. Roser F, Tatagiba M, Maier G. Spinal robotics: current applications and future perspectives. Neurosurgery 2013;72 Suppl 1:12-8.

23. Schatlo B, Molliqaj G, Cuvinciuc V, et al. Safety and accuracy of robotassisted versus fluor-oscopy-guided pedicle screw insertion for degenerative diseases of the lumbar spine: a matched cohort comparison. J Neurosurg Spine 2014;20:636-43.

24. Kim HJ, Lee SH, Chang B, et al. Monitoring the Quality of Robot-Assisted Pedicle Screw Fix-ation in the Lumbar Spine by Using a Cumulative Summation Test. Spine 2015;40:87-94.

25. Lonjon N, Chan-Seng E, Costalat V, et al. Robot-assisted spine surgery: feasibility study through a prospective casematched analysis. Eur Spine J 2016;25:947-55.

26. Le X, Tian W, Shi Z, et al. Robot-Assisted Versus Fluoroscopy-Assisted Cortical Bone Tra-jectory Screw Instrumentation in Lumbar Spinal Surgery: A MatchedCohort Comparison. World Neurosurg 2018;120:e745-51.

27. Jin $M$, Liu Z, Liu X, et al. Does intraoperative navigation improve the accuracy of pedicle screw placement in the apical region of dystrophic scoliosis secondary to neurofibromatosis type I: comparison between O-arm navigation and free-hand technique. Eur Spine J 2016;25:1729-37.

28. Macke JJ, Woo R, Varich L. Accuracy of robot-assisted pedicle screw placement for adolescent idiopathic scoliosis in the pediatric population. J Robot Surg 2016;10:145-50.
29. Ohrt-Nissen S, Dahl B, Gehrchen M. Choice of Rods in Surgical Treatment of Adolescent Idiopathic Scoliosis: What Are the Clinical Implications of Biomechanical Properties? - A Review of the Literature. Neurospine 2018;15:123-30.

30. Lehman RA Jr, Lenke LG, Helgeson MD, et al. Do intraoperative radiographs in scoliosis surgery reflect radiographic result? Clin Orthop Relat Res 2010;468:679-86.

31. Oren JH, Tishelman JC, Day LM, et al. Measurement of Spinopelvic Angles on Prone In-traoperative LongCassette Lateral Radiographs Predicts Postoperative Standing Global Alignment in Adult Spinal Deformity Surgery. Spine Deform 2019;7:325-30.

32. Vaynrub M, Hirsch BP, Tishelman J, et al. Validation of prone intraoperative measurements of global spinal alignment. J Neurosurg Spine 2018;29:187-92.

33. Lovecchio F, Qureshi SA. The Current State of Minimally Invasive Approaches to Adult Spinal Deformity. Curr Rev Musculoskelet Med 2019;16:318-27.

34. Smith JS, Klineberg E, Lafage V, et al. Prospective multicenter assessment of peri- operative and minimum 2-year postoperative complication rates associated with adult spinal de-formity surgery. J Neurosurg Spine 2016;25:1-14.

35. Hayda RA, Hsu RY, DePasse JM, et al. Radiation Exposure and Health Risks for Orthopaedic Surgeons. J Am Acad Orthop Surg 2018;26:268-77.

36. Chou LB, Lerner LB, Harris AH, et al. Cancer prevalence among a cross-sectional survey of female orthopedic, urology, and plastic surgeons in the United States. Womens Health Issues 2015;25:476-81.

37. Smith HE, Welsch MD, Sasso RC, et al. Comparison of radiation exposure in lumbar pedicle screw placement with fluoroscopy vs computer-assisted image guidance with intraoperative three-dimensional imaging. J Spinal Cord Med 2008;31:532-7.

38. Tabaraee E, Gibson AG, Karahhalios D, et al. Intraoperative cone beam-computed tomog-raphy with navigation (O-ARM) versus conventional fluoroscopy (C-ARM): a cadaveric study comparing accuracy, efficiency, and safety for spinal instrumentation. Spine (Phila $\mathrm{Pa}$ 1976) 2013;38:1953-8.

39. Villard J, Ryang YM, Demetriades AK, et al. Radiation exposure to the surgeon and the patient during posterior lumbar spinal instrumentation: a prospective randomized comparison of navigated versus non-navigated freehand techniques. Spine (Phila Pa 1976) 2014;39:1004-9. 
40. Costa F, Tosi G, Attuati L, et al. Radiation exposure in spine surgery using an image-guided system based on intraoperative cone-beam computed tomography: analysis of 107 consecutive cases. J Neurosurg Spine 2016;25:654-9.

41. Mendelsohn D, Strelzow J, Dea N, et al. Patient and surgeon radiation exposure during spinal instrumentation using intraoperative computed tomography-based navigation. Spine J 2016;16:343-54.

Cite this article as: Boddapati V, Lombardi JM, Urakawa $\mathrm{H}$, Lehman RA. Intraoperative image guidance for the surgical treatment of adult spinal deformity. Ann Transl Med 2021;9(1):91. doi: 10.21037/atm-20-2765
42. Vaishnav AS, Merrill R, Sandhu H, et al. A Review of Techniques, Time-demand, Radiation Exposure and Outcomes of Skin-anchored Intra-operative 3D Navigation in Minimally Invasive Lumbar Spinal Surgery. Spine (Phila Pa 1976) 2020;45:E465-76.

43. Ahern DP, Gibbons D, Schroeder GD, et al. Imageguidance, Robotics, and the Future of Spine Surgery. Clin Spine Surg 2020;33:179-84. 